\title{
Numerical analysis of changing the force factors in temporary lining at the tunnel construction by the NATM
}

\author{
Volodymyr Kuprii ${ }^{1, *}$, Volodymyr Petrenko ${ }^{1}$, Sofiia Kuprik ${ }^{1}$, and Yevhenii Kripak $^{2}$ \\ ${ }^{1}$ Dnipro National University of Railway Transport named after Academician V. Lazaryan, 49010, \\ Dnipro, Lazaryan Str., 2, Ukraine \\ ${ }^{2}$ Yenon - Research \& Design Ltd., 30200, Tirat Carmel, Yozma Str., 4, Israel
}

\begin{abstract}
The paper presents the results of a numerical analysis of force factors in temporary lining at the tunnel construction by New Austrian Tunneling Method (NATM). The relevance of the performed research is substantiated by the complexity of the temporary lining operation in the form of arches combination, anchors, and shotcrete that arose during construction of the Beskydskyi tunnel in Ukraine. NATM, used in construction, is associated with a change in the sectional area of the working and a staged installation of temporary lining, which leads to a gradual change in the stress-strain state of the "temporary lining surrounding massif" system. In turn, this leads to a change in the force factors (bending moments and normal forces) in temporary lining. In this study, a series of finite-element models simulating the stages of rock excavation and installation of lining elements have been developed and analyzed. The obtained results allowed to determine the cardinal change of force factors in temporary lining, depending on the stage of construction. Changing the force factors at different stages of the tunnel construction by the NATM makes it possible to perform an optimal selection for temporary lining location.
\end{abstract}

\section{Introduction}

In modern methods of constructing the transport tunnels, for example, in NATM one, temporary lining is widely used [1-3]. The level of analytical calculation methods does not allow to perform its optimal selection, since the lining operation depends on the change of the stress-strain state in "temporary lining - surrounding massif" system $[4,5]$.

Temporary lining by other methods of the tunnels construction is intended to support the working only near the face until the moment of installing the permanent one and ensuring safe conditions for the operation on the mining the face and construction of permanent lining [6]. During the tunnels construction by the NATM, after the rock excavation to the construction of a permanent lining, a lot of time passes, so temporary lining takes on not only the role of the working support, but also actively interacts with the

\footnotetext{
*Corresponding author: kypriy@i.ua
} 
surrounding massif [7].

Temporary lining of workings in the tunnels construction by NATM is often combined and consists of arches, anchors, and shotcrete (in various combinations). It must meet the technical, technological and economic requirements, the list of which is quite wide, and their classification by categories is, in a sense, conditionality. It is simultaneously impossible to meet all the requirements for lining, due to their mutual contradictions (for example, bearing capacity and cost, strength of the element and its mass, etc.).

The effectiveness in applying the temporary lining depends on the optimal choice of its parameters, which is possible only with due consideration of all factors affecting the bearing capacity of the structure. The purpose of the paper is to carry out a numerical analysis of the force factors (bending moments and normal forces) of temporary lining in the transport tunnel being constructed by NATM, and an important factor is taking into account the change of the stress-strain state of the "temporary lining - surrounding massif" system when rock excavation in parts.

\section{Methods}

In the tunnels construction by NATM, a situation arises where the upper part of the section (calotte) is fixed for a long time by temporary lining, while parallel work is carried out on the drivage in the lower part of the section (stross) (Fig. 1).

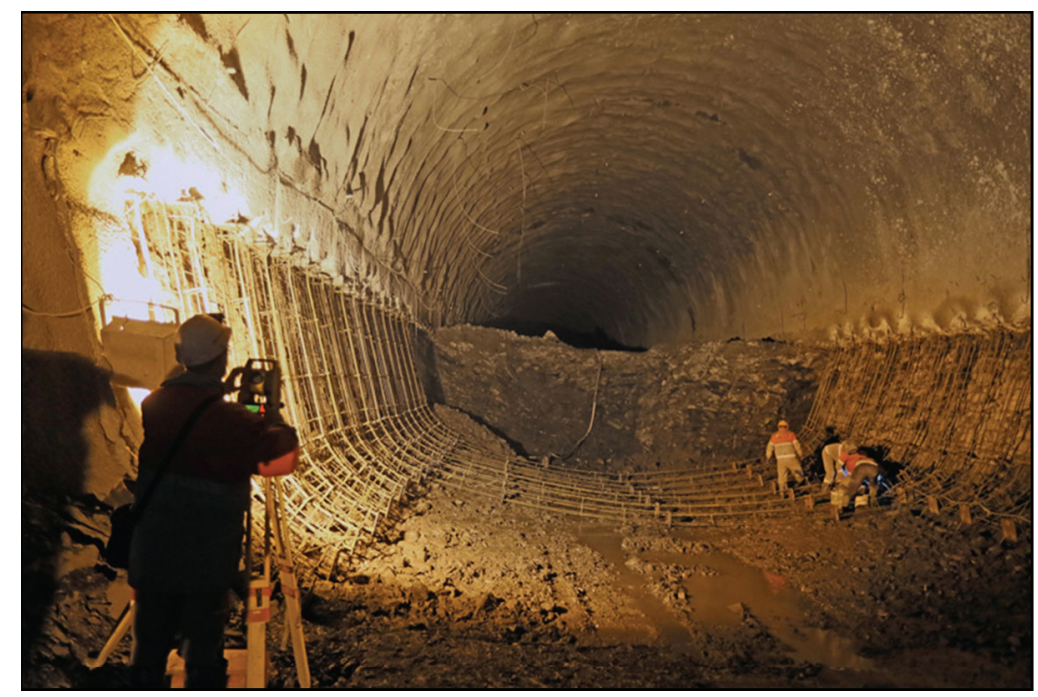

Fig. 1. Works on the installation of temporary lining of the trough part at the stross in the Beskydskyi tunnel (Ukraine).

The change in the sectional area and installation of additional lining (arch legs supporting the calotte, reinforcement lining of the trough part, anchors, and shotcrete) fundamentally change the stress-strain state of the "temporary lining - surrounding massif" system and force factors in temporary lining [8]. Mathematical modeling by multifunctional software complex LIRA of a series of models simulating the staged operation makes it possible to analyze the change in them of force factors when changing the stress-strain state of the surrounding massif $[9,10]$.

Software complex LIRA (license number 1d/2063) implements the finite element method in the variational formulation. The general form of the equation of the potential energy of deformation of a body and the potential of external forces is established from the 
analysis of equations. They are obtained by way of expressing the potential energy of deformation $U$ as a function of displacements (using the Cauchy equation):

$$
U(u, v, w)=G \iiint_{V}\left\{\begin{array}{l}
\frac{1-\mu}{1-2 \mu}\left[\left(\frac{\partial u}{\partial x}\right)^{2}+\left(\frac{\partial v}{\partial y}\right)^{2}+\left(\frac{\partial w}{\partial z}\right)^{2}\right]+ \\
+\frac{2 \mu}{1-2 \mu}\left[\frac{\partial u}{\partial x} \frac{\partial v}{\partial y}+\frac{\partial v}{\partial y} \frac{\partial w}{\partial z}+\frac{\partial w}{\partial z} \frac{\partial u}{\partial x}\right]+ \\
+\frac{1}{2}\left[\left(\frac{\partial u}{\partial x}+\frac{\partial v}{\partial x}\right)^{2}+\left(\frac{\partial v}{\partial z}+\frac{\partial w}{\partial y}\right)^{2}+\left(\frac{\partial w}{\partial x}+\frac{\partial u}{\partial z}\right)^{2}\right]
\end{array}\right\} d V,
$$

where $u, v, w$ - the displacement of vertices of elements; $\mu$ - Poisson's ratio; $G$ shear module; $V$ - the volume of the element.

Then the potential of external forces is expressed by the equation:

$$
U(Q, P)=\iiint_{V}\left(Q_{x} u+Q_{y} v+Q_{z} w\right) d V-\iint_{\Omega}\left(P_{x} u+P_{y} v+P_{z} w\right) d \Omega,
$$

where $Q_{x}, Q_{y}, Q_{z}, P_{x}, P_{y}, P_{z}$ - axis projection on the $x, y, z$ of volume $V$ and surface $\Omega$ forces respectively.

The expression of the potential energy of deformation of a body can be written in the matrix form as follows:

$$
U(u, v, w)=\frac{1}{2}\{U\}^{T}[K]\{U\}
$$

where $[K]$ - matrix of rigidity; $\{U\}^{T},\{U\}$ - transposed and non-transposed vector of displacements of vertices of elements, respectively.

The soil in the software complex LIRA software is given by a universal finite element FE 30 intended for the solution of the plane problem of the theory of elasticity. The material is uniform in thickness, isotropic, linearly elastic. With the help of the software complex LIRA a number of "temporary lining - surrounding massif" models have been designed, which simulate the staged operation upon the rock excavation and installation of temporary lining (Fig. 2, 3).

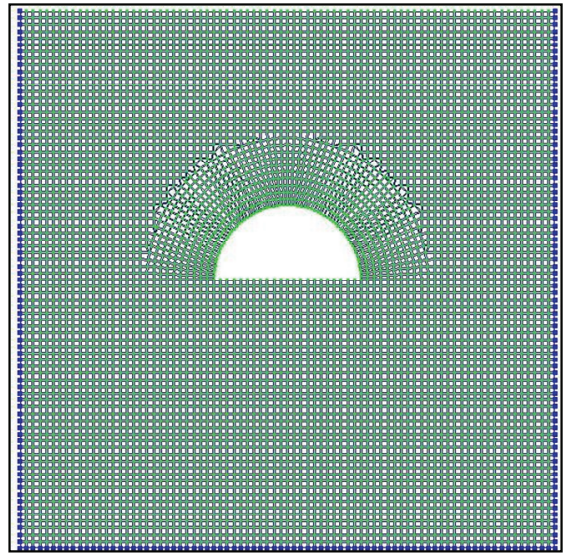

Fig. 2. Initial finite-element model "temporary lining - surrounding massif". 


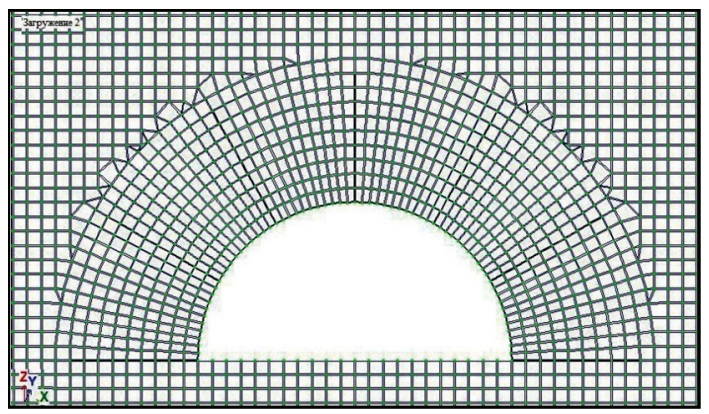

a)

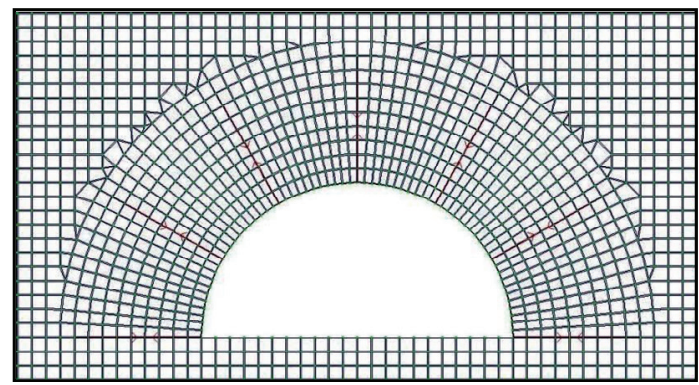

b)

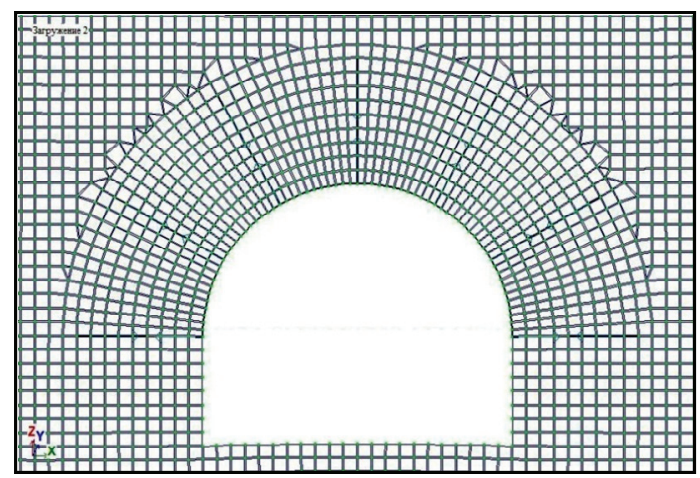

c)

Fig. 3. Fragments of finite-element models "temporary lining - surrounding massif": a) stage 1 "Installation of temporary lining elements in the calotte" (without anchor tensioning); b) stage 2 "Installation of temporary lining elements in the calotte" (with anchor tensioning); c) stage 3 "Stross opening".

To increase the accuracy of calculation and its realism to field conditions of interaction in the "temporary lining - surrounding massif" system, a rock massif of $40 \times 40$ meters is created around the working, discretized on finite elements of $0.5 \times 0.5 \mathrm{~m}$, the type of elements "plate", which allows simulating the work of rocky ground. Deformation properties and the specific weight of the rock are as follows: elastic modulus is $210000 \mathrm{kN} / \mathrm{m}^{2}$; Poisson ratio is 0.2 ; specific weight is $22 \mathrm{kN} / \mathrm{m}^{2}$. Also, temporary lining is provided - an arch in the form of $\mathrm{H}$ beam with parallel flanges, type B (H-beam 20B1). At the second and third stages an anchor is used with a diameter of $20 \mathrm{~mm}$, a length of $4 \mathrm{~m}$ with a maximum permitted fracture force of $80 \mathrm{kN}$ (tensioning by force of $10 \mathrm{kN}$ is taken).

For more accurate discretization of finite-element models, the "creation and triangulation of contours" tool is applied, and in the area of the arch, which has a rounded form, the tool is a "torsional surface". The load is the load from its own weight. 


\section{Results and discussion}

Figures 4 and 5 show the force factors in temporary lining (arch with anchors), depending on the stages of the tunnel construction by NATM.

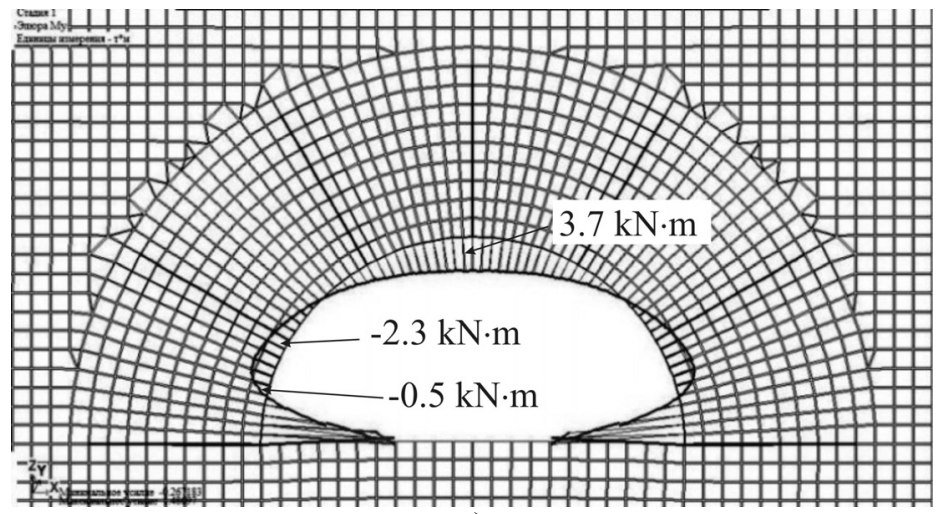

a)

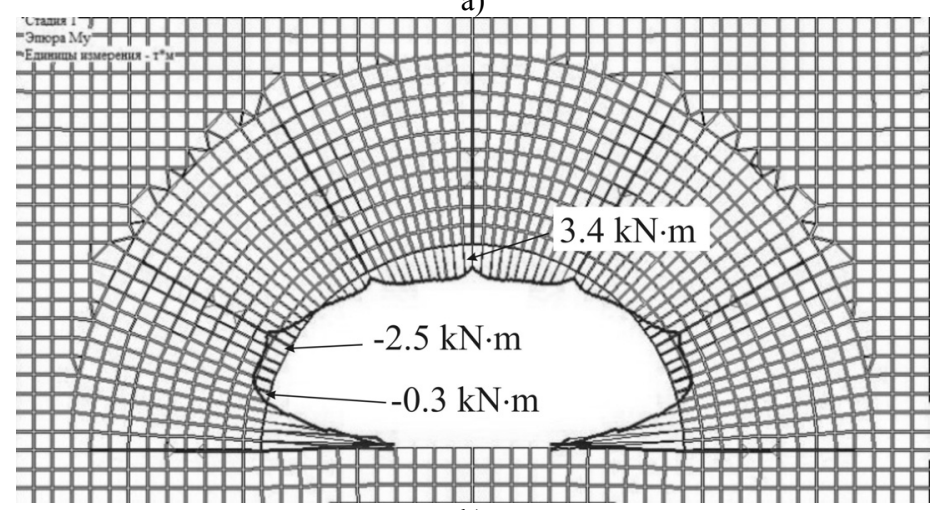

b)

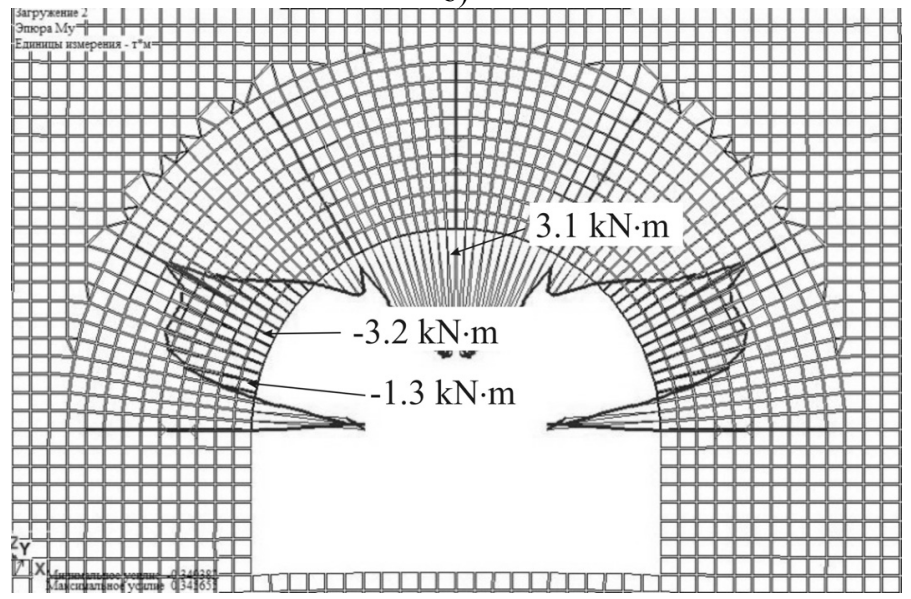

c)

Fig. 4. Bending moment diagrams depending on the stage of the tunnel construction: a) stage 1 "Installation of temporary lining elements in the calotte" (without anchor tensioning); b) stage 2 "Installation of temporary lining elements in the calotte" (with anchor tensioning); c) stage 3 "Stross opening". 


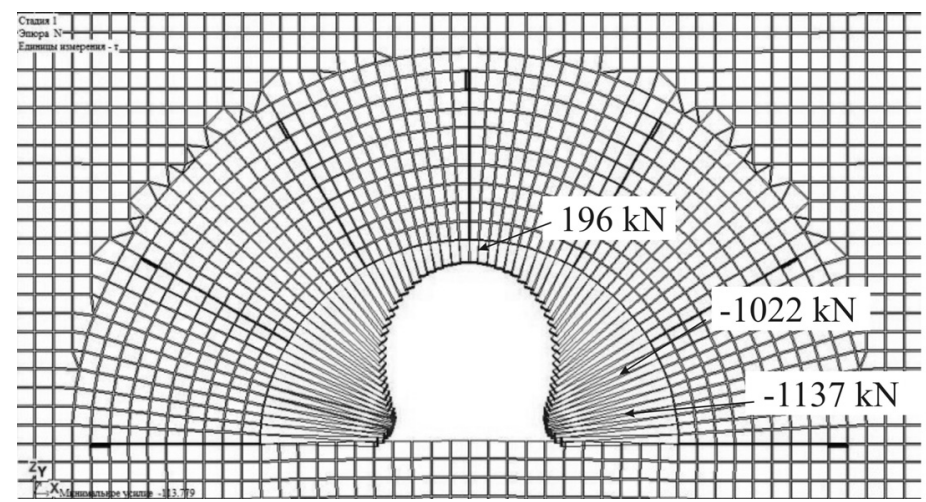

a)

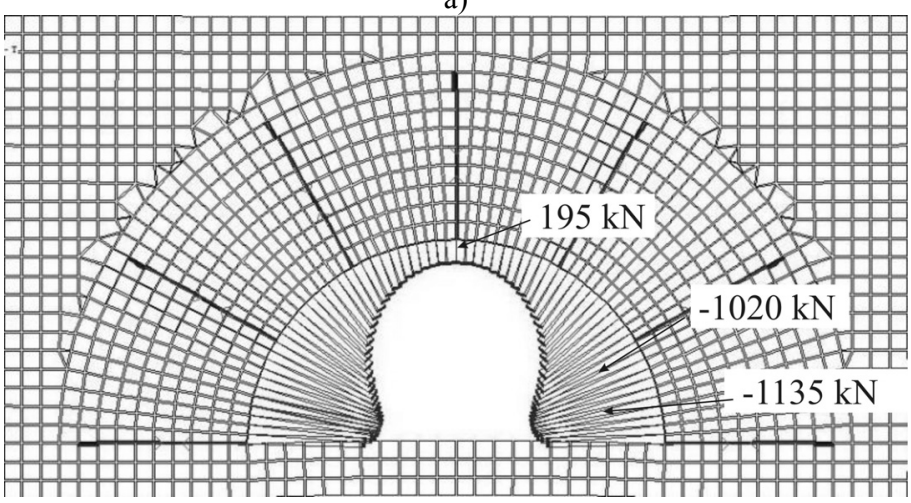

b)

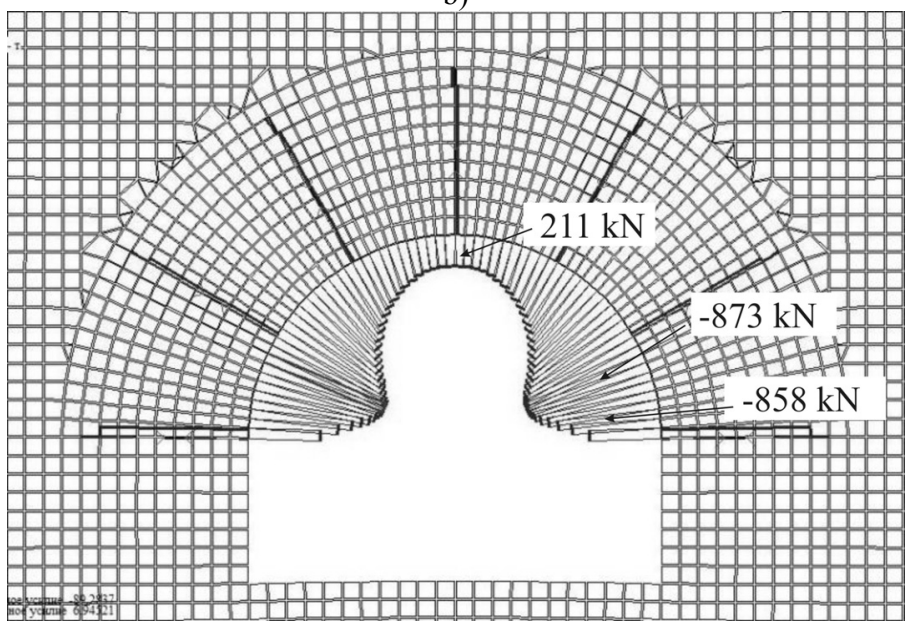

c)

Fig. 5. Diagrams of normal forces depending on the stage of the tunnel construction: a) stage 1 "Installation of temporary lining elements in the calotte" (without anchor tensioning); b) stage 2 "Installation of temporary lining elements in the calotte" (with anchor tensioning); c) stage 3 "Stross opening".

Table 1 shows the values of force factors in characteristic points of temporary lining, the positions of which are represented on Figure 6. 


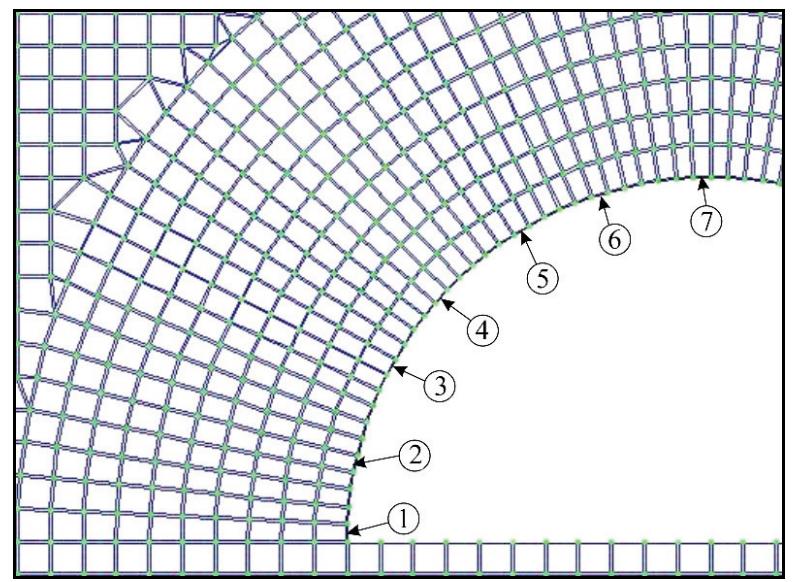

Fig. 6. Scheme position of characteristic points of temporary lining.

Table 1. Force factors of temporary lining (arch).

\begin{tabular}{|c|c|c|c|c|c|c|}
\hline $\begin{array}{c}\text { Characteristic points of } \\
\text { temporary lining }\end{array}$ & \multicolumn{3}{|c|}{ Bending moments, kN·m } & \multicolumn{3}{c|}{ Normal forces, kN } \\
\cline { 2 - 7 } & Stage 1 & Stage 2 & Stage 3 & Stage 1 & Stage 2 & Stage 3 \\
\hline Point 1 (fifth) & 0 & 0 & 0 & -1026 & -1026 & -499 \\
\hline Point 2 & -0.5 & -0.3 & -1.3 & -1137 & -1135 & -858 \\
\hline Point 3 & -2.3 & -2.5 & -3.2 & -1022 & -1020 & -873 \\
\hline Point 4 & -0.53 & 0.1 & -0.2 & -792 & -737 & -677 \\
\hline Point 5 & 1.6 & 1.4 & 0.9 & -491 & -489 & -473 \\
\hline Point 6 & 2.9 & 3.2 & 2.9 & -296 & -291 & -299 \\
\hline Point 7 (lock) & 3.7 & 3.4 & 3.1 & -196 & -195 & -211 \\
\hline
\end{tabular}

As follows from the analysis findings of the conducted research, the combined temporary lining during the tunnel construction by NATM has important advantages, since to a certain extent, the interaction in the "lining - massif" system is applied. This is confirmed by the values of force factors listed in Table 1 .

\section{Conclusions}

The conducted research allow for the following conclusions. First of all, the values of normal forces at all three stages in the operation of calotte temporary lining and stross opening are reduced from five to the lock at 2.35 to 5.35 times, depending on the stage of construction. In this case, a smaller value is characteristic for the third stage of the construction, that is, when stross opening.

At the same time, the bending moments at the lining points from five to the lock increase from 2.4 to 11.3 times, and a smaller value is also characteristic of the third stage of construction (stross opening). Thus, the application of optimal combinated lining allows to effectively solve the problem in the implementation of NATM in Ukraine.

\section{References}

1. E.T. Brown, TTNA, 13, 10 (1981)

2. W. Wittke, B. Pierau, C. Erichsen New Austrian Tunneling Method (NATM) - Stability Analysis and Design (WBI GmbH, 2006)

3. C.W.W. Ng, K.M. Lee, D.K.W. Tang Can. Geotech. J., 41, 3 (2004) 
4. Zaslavskiy, Yu.Z., Druzhko, E.B. (1989). Novyye vidy krepi gornykh vyrabotok. Moskva: Nedra

5. Litvinskiy, G.G., Fesenko, E.V., Emets, E.V. (2011). Raschet krepi gornykh vyrabotok na EVM. Alchevsk: DonGTU

6. Bulat, A.F., Vinogradov, V.V. (2002). Oporno-ankernoye krepleniye gornykh vyrabotok ugolnykh shakht. Dnepropetrovsk: Vilpo

7. Koskov, I.G. (1987). Novyye materialy i konstruktsii krepi gornykh vyrabotok. Moskva: Nedra

8. Petrenko, V.D., Tiutkin, O.L., Proskurnia, S.T. (2016). Features of drilling-and-blasting at construction Beskidskiy tunnel. Science and Transport Progress. Bulletin of Dnipropetrovsk National University of Railway Transport, 5 (65), 178-185

9. Petrenko, V.D., Tiutkin, O.L., Hrebin, A.V. (2006). Matematychne modeliuvannia poetapnoho protsesu rekonstruktsii obrobky zaliznychnoho tuneliu, Stroitelstvo, materialovedeniye, mashinostroyeniye, 37, 352-359

10. Frolov, Yu.S., Mordvinkov, Yu.A. (2006). Sistema «krep - gruntovyy massiv». Chislennyy analiz napryazhenno-deformirovannogo sostoyaniya s uchetom tekhnologii prokhodki tonneley. Metro i tonneli, 5, 32-353 